\title{
Editorial
}

\section{Is barber shops a source of HIV transmission in India?}

\author{
Kurien Thomas* \\ Professor of Medicine, Director of Research, Oman Medical Specialty Board, Way No: 993, Block 3, Al Khoud, Muscat, \\ IndiaCLEN Network, Oman
}

\section{A R T I C L E I N F O}

Article history:

Received 28 April 2013

Accepted 10 May 2013

Available online 6 June 2013

In this issue of the journal Nath et $\mathrm{al}^{1}$ have presented data on a potential behavior at risk for HIV transmission by road-side barbers from Kanpur, India. It certainly is of concern that the services of barbers who have poor knowledge and bad hygienic practices are accessed widely by many in the community without realizing the consequences. But we must raise the question whether the primary concern should be with regard to HIV transmission or with regard to transmission of other blood borne viruses especially Hepatitis B (HBV) and Hepatitis C (HBC).

Fortunately for all, HIV virus is relatively susceptible to drying and exposure to sunlight. It survives out side the body for only for a few minutes. ${ }^{2}$ The concentration of HIV virus in the blood is also comparatively less than HBV and HBC. Hence hepatitis virus is much more easily transmitted by unhygienic techniques and unsafe practices than HIV. From an epidemiological perspective, the contribution of HIV transmission in India is primary by sexual route $(\sim 86 \%)$. The other significant modes of transmission include blood transfusion, perinatal transmission through contaminated needles by injecting drug users. This does not mean that HIV transmission does not occur through barber shops through unhygienic methods. It only means that the contribution to the HIV epidemic is probably relatively negligible from national level in perspective.
In many parts of India HBV surface antigen positivity is more than $4 \%(2.4 \%-15.9 \%) .{ }^{3}$ Most of this transmission occur in the early infancy. However new cases are added to the pool of positives at a rate very similar to the rate of surface antigen clearance every year so that the percentage of positives in the community seems to be more or less stable across the adult age group. ${ }^{4}$ The consequence of this transmission and its long term implication in the incidence of cirrhosis and hepato-cellular carcinoma (HCC) is of grave significance. There is increasing burden of end stage liver disease, chronic liver disease and HCC in the community. Treatment of these conditions is prohibitively costly and is not available and accessible to most people in India.

The success of effort of National AIDS Control Organization (NACO) in reducing the burden of HIV prevalence at national level is well documented. The prevalence has declined from $0.41 \%$ in 2000 to $0.31 \%$ in $2009 .^{5}$ The estimated number of new annual HIV infections at the national level has declined by more than $50 \%$ over the past decade. ${ }^{5}$ Dynamic disease control models have shown that over the next 10 years HIV epidemic will be substantially controlled if the nation continues to focus on proven and effective strategies of combining prevention with care and support. ${ }^{6}$ However there are many districts in so called low prevalence states in India

* Tel.: +96894103438.

E-mail addresses: kurien123@gmail.com, kurien123@hotmail.com (K. Thomas). 
like UP, that is showing signs of emerging epidemic. These emerging districts and sub-epidemics are related to population migration, and lack of focus on preventive measures. Kanpur is one of the industrial centers of UP with considerable migrant population. The low awareness regarding HIV transmission noted in the study $(0-5.6 \%)^{1}$ among road-side barbers is of special concern and may point to lack of focus on IEC and other preventive strategies in this geographical area. It is important to bring this to the notice of the state AIDS Control Organization and NACO.

Though the results of the study may not be of major concern with regard to HIV epidemic in India, it has implications on other blood borne infections. There is greater need for effective strategies to control transmission of HBV and HCV in the community. Vaccination and ensuring improved hygienic practices are the best answers to this problem. I am sure that the information generated in the article will help us to refocus our efforts in strengthening the strategies to control blood borne infections in the country.
R E F E R E N C E S

1. Nath B, Kumari R, Midha T, Vaswani ND, Lekhwani S. Profession of barbering: unexplored issues in HIV/AIDS. CEGH. 2013;1.

2. Von Reyn CF, Mann JM, Chin J. International travel and HIV infection. WHO Bull. 1990;68:251-259.

3. Batham A, Narula D, Toteja T, Sreenivas V, Puliyel JM. Systematic review and meta-analysis of prevalence of hepatitis B in India. Indian Pediatr. 2007;44:664-674.

4. Kurien T, Thyagarajan SP, Jeyaseelan L, et al, STD Study Group. Community prevalence of hepatitis B virus infection and modes of transmission in Tamil Nadu, India. Indian J Med Res. 2005;121:670-675.

5. National AIDS Control Organization, Ministry of Health \& Family Welfare, Government of India. State Fact Sheet (Internet) 2012; March 2012. Available from: http://www.nacoonline.org/ NACO/Quick_Links/Publication/State_Fact_Sheets/.

6. Arni SR, Kurien T, Sudhakar K, Philip KM. HIV/AIDS epidemic in India and predicting the impact of the national response: mathematical modeling and analysis. Math Biosci Eng. 2009;6:779-813.

\section{IndiaClen recommendations for improving postgraduate medical research \& publication}

IndiaClen 2013 Annual Conference Group (ACG), Jyotsna Agarwal ${ }^{a}$, Madhuri Kulkarni ${ }^{b}$, Uday Mohan ${ }^{c}$, Vinita Das ${ }^{d}$, Vinita Singh ${ }^{e}$, Siddharth Das ${ }^{f}$, Pankaj Bhardwaj ${ }^{g}$, Pragna Rao ${ }^{h, i}$, Sanjay Mehendale ${ }^{j}$, Vimala Venkatesh ${ }^{a}$, Archana Kumar ${ }^{k}$, Nandini Kumar ${ }^{l}$, Nuzhat Hussain ${ }^{m}$, Pankaja Ravi Raghav ${ }^{n}$, Ranabir Pal ${ }^{\circ}$, Apul Goel ${ }^{p}$, Rashmi Kumar ${ }^{q}$, Farzana Beg ${ }^{r}$, Ashraf Malik ${ }^{s}$, Raj Mohan Pillai ${ }^{\mathrm{t}}$, Vinod Paul ${ }^{u}$, Sushil Kumar Kabra ${ }^{v}$, Ravindra Mohan Pandey ${ }^{w}$, L. Jeyseelan ${ }^{x}$, Suresh Ughade ${ }^{y}$, Prathap Tharyan ${ }^{z}$, Jai Veer Singh ${ }^{a a}$, Raj Mehrotra ${ }^{b b, c c}$, V.N. Tripathi ${ }^{\text {dd }}$, Neeraj Mohan Srivastava ${ }^{e e}$, Priya Tripathi ${ }^{f f}$, Akansha $^{99}$, Arpita ${ }^{9 g}$, Tavishi Srivastava ${ }^{9 g}, J^{9 h n v i}{ }^{9 g}$, Raj Gaurav Singh ${ }^{g 9}$, Sarika Gupta ${ }^{\text {hh }}$, Aditya Vidyasagar ${ }^{\text {ii }}$, S. Chakraborty jij, Shally Awasthi ${ }^{k k, l l, *}$

\footnotetext{
a Professor, Department of Microbiology, KGMU, Lucknow, India

${ }^{\mathrm{b}}$ Professor, Department of Pediatrics, LTM Medical College and Hospital, Mumbai, India

${ }^{\mathrm{c}}$ Professor, Department of Community Medicine, KGMU, Lucknow, India

${ }^{\mathrm{d}}$ Professor \& Head, Department of Obstetrics \& Gynecology, KGMU, Lucknow, India

e Professor \& Head, Department of Ophthalmology, KGMU Lucknow, India

${ }^{\mathrm{f}}$ Professor \& Head, Department of Rheumatology, KGMU Lucknow, India

${ }^{g}$ Assistant Professor, Community Medicine \& Family Medicine, AIIMS, Jodhpur, India

${ }^{\mathrm{h}}$ Professor \& Head, Department of Bio-Chemistry, Kasturba Medical College, Manipal, India
}

\footnotetext{
* Corresponding author.

E-mail address: Shally07@gmail.com (S. Awasthi).
} 